\title{
Application of martensitic SMA alloys as passive dampers of GFRP laminated composites
}

\author{
M. Bocciolone, M. Carnevale, A. Collina, N. Lecis, A. Lo Conte, B. Previtali \\ Politecnico di Milano, Department of Mechanical Engineering, Via La Masa, 1 Milano (Italy) \\ C.A. Biffi, P.Bassani, A. Tuissi \\ National Research Council CNR, Institute for Energetics and Interphases, Corso Promessi Sposi, 29 Lecco (Italy)
}

\begin{abstract}
This paper describes the application of SMA (Shape Memory Alloy) materials to enhance the passive damping of GFRP (Glass Fiber Reinforced Plastic) laminated composite. The SMA has been embedded as reinforcement in the GFRP laminated composite and a SMA/GFRP hybrid composite has been obtained. Two SMA alloys have been studied as reinforcement and characterized by thermo-mechanical tests. The architecture of the hybrid composite has been numerically optimized in order to enhance the structural damping of the host GFRP laminated, without significant changes of the specific weight and of the flexural stiffness. The design and the resultant high damping material are interesting and will be useful in general for applications related to passive damping. The application to a new designed lateral horn of railway collector of the Italian high speed trains is discussed.
\end{abstract}

KEYWORDS. SMA hybrid composite; Structural damping; Laser micro-cutting; Railway collector.

\section{INTRODUCTION}

$\mathrm{O}$ ver the past few years, due to the increasing technological demand for the passive suppression of mechanical vibrations, there has been a growing interest in developing high damping materials. While a consistent amount of literature on the damping of SMAs (Shape Memory Alloys) has focused on the active damping of smallamplitude vibrations devoted either to applications of pseudoelasticity or during the superelastic phase, less attention has been paid to the passive damping behaviour at small amplitude harmonic vibrations with varying frequency ranges. Small amplitude and passive vibration damping can be important in mechanical applications, where random broadband excitations are present in a typical operational environment.

Shape memory alloys are characterized by two phases: an austenitic phase, obtained at high temperatures and a martensitic one, obtained at low temperatures; the direct and reverse phase transformation between the two phases occurs in a certain temperature range, depending on the composition and heat treatment of the alloy [1]. High damping can be observed during direct and reverse transformations, and, consequently, during limited temperature intervals. Several types of shape memory alloys, such as Cu based SMAs, show high values of internal friction, even in the martensitic state [2-4].

The fairly high intrinsic damping of these martensitic phases has been associated with the atoms and defect motion and with the re-orientation of the martensite twin variants under stress [5]. From a practical point of view, this intrinsic energy dissipation mechanism of the martensitic phase over wider temperature ranges offers an interesting perspective for the application of SMA alloys in the martensitic state as passive dampers of low amplitude mechanical vibrations for automotive, aerospace and other dynamic applications $[6,7]$ The idea of adopting the damping properties of the martensitic state means that the service temperature has to be lower than the transformation temperature. 
The high cost, the relatively high specific weight, and the relatively low specific modulus preclude the use of monolithic SMA as a bulk material in many structures; however, interesting examples of composites or hybrid composites, designed for damping, can be found in literature $[8,9]$.

Since the concept of SMA hybrid composites was first proposed in 1988 by Rogers et al. [10], these composites have attracted enormous attention in terms of improving creep and fatigue properties [11], strength [12] and damping capacity [13], as well as to control the shape or vibration response property [14]. Among these materials, the SMA/Glass-Fiber Reinforced Plastic (GFRP) hybrid composite - in which the embedded SMA is used to improve structural damping, thereby saving weight and stiffness, is especially important due to the wide potential or effective technological application of GFRP in all, real-life engineering environments $[15,16]$.

This paper describes a new architecture of SMA/GFRP hybrid composite numerically optimized in order to enhance the structural damping of the host GFRP laminated, without significant changes of the specific weight and of the flexural stiffness [7].

Two SMA alloys have been studied as reinforcement and characterized by termo-mechanical tests.

The design and the resultant high damping material are interesting and will be useful in general for applications related to passive damping, i.e. wind turbine blades or automotive components. Since the research began from studies about the dynamic optimization of the collector of the Italian high speed trains, this application is the guideline of the paper.

\section{DESIGN CONSIDERATIONS}

he flexural modes of the collector of the high-speed train (Fig. 1) play a significant role in terms of its dynamic behaviour and its lateral horns - usually made of fiber glass/epoxy resin laminated - are not able to guarantee the required level of structural damping. To optimize the dynamic behaviour of the collector, structural damping must be enhanced, in order to avoid in-depth modification in terms of mass and stiffness $[17,18]$.

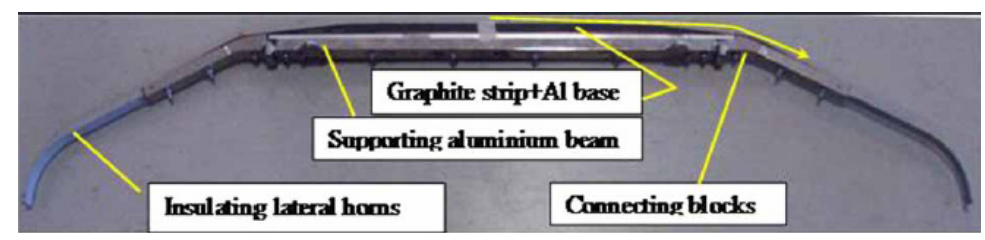

Figure 1: Italian high-speed train collector.

To enhance the damping of a Glass Fiber Reinforced Polymer (GFRP) beam and shell through passive vibration suppression, a shape memory alloy (SMA) can either be embedded as reinforcement in the GFRP part. Unlike GFRP, SMA alloys have a higher storage modulus and a higher specific damping $[19,20]$. Due to its higher storage modulus and, assuming that the interface guarantees the right load transfer, the SMA material is capable of storing more specific elastic energy than the GFRP and, as consequence, is able to take maximum advantage of its higher specific damping in order to enhance the structural damping of the hybrid composite. Therefore the partial substitution of the GFRP material with SMA material in various shapes and forms is expected to significantly increase the damping properties of the hybrid composite.

In [21], thanks to the high damping of the NiTi in its martensitic the authors proposed the application of Ti-Ni SMA alloy wires as "smart fibers" embedded in this conventional GFRP material in order to create new horns with an enhanced flexural damping capacity related to the first flexural mode. Two series of 13 wires, with a diameter of 0.56 mm, were embedded below the upper and the lower surfaces of the horn as shown in Fig. 2.

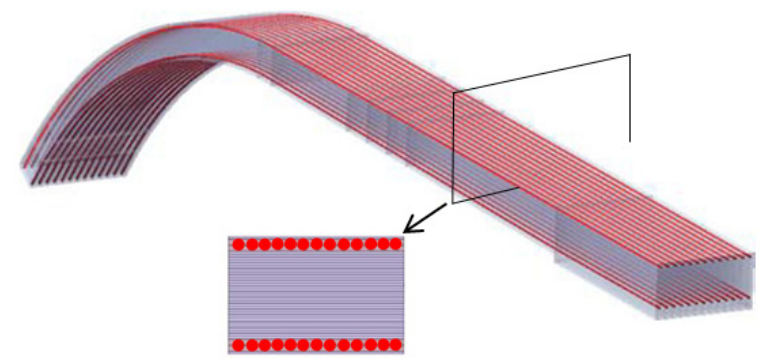

Figure 2: Lateral horn made from a GFRP laminated composite with two layers of embedded NiTi wires. 
A first prototype of the horn was manufactured and then tested dynamically in a laboratory. Experimental results showed that not only do the NiTi wires collaborate in the composite but also that the non-dimensional damping of the first flexural mode increases by about $11 \%$ with respect to the non-dimensional damping of the original horn made only of GFRP. Conversely, the first natural frequency increases by about $5 \%$. According to these results, it can be expected that the higher level of the vibration damping, required for real application of the proposed architecture of the horn, can be obtained with a proper volume fraction of the SMA wires; however, the conflicting consequences of the introduction of SMA wires between increasing of the structural damping and increasing of the first natural frequencies is addressed. For this reason, the same paper also discusses the implementation of a FE model of the horn in order to perform a dynamic analysis and to calculate the related non-dimensional damping. The results are presented for three configurations: the horns in their original configuration (only GRFP), the horns made from GRRP with two series of 13 embedded wires, as in the real prototype shown in Fig. 3, and the horn made from GRRP with two series of 20 embedded wires. As expected, by increasing the number of wires, the vibration damping of the horn increases; however, the undesirable side effect of the NiTi wires is that the flexural frequency increases by $10 \%$, thus indicating that the requirements of the renewed design cannot be satisfied. Additionally, some consideration should also be given to the architecture of the lateral horn with embedded SMA wires. The manufacturing process involved in positioning the wires within the matrix is very complex. Furthermore, when the horn is cooled to room temperature, high residual stresses in the SMA wires are expected, due to the mismatch between the thermal expansion coefficients of the SMA material and the laminated GFRP composite. As a consequence, SMA fiber pull-out can easily occur [22].

The information generated and the experience gained in our previous paper will be used to propose a new SMA/GFRP hybrid composite, based on a synergistic contribution of the parameters associated with the SMA material such as specific damping, specific stiffness and volume fraction as well as those associated with the host, including flexural rigidity, SMA through-the-thickness location and SMA-host interfacial strength. Particular attention has been paid to manufacturability and the cost-effectiveness of the component made with the proposed new composite.

\section{THE ARCHITECTURE OF THE NEW HYBRID COMPOSITE}

$\mathrm{T}$

he architecture of the new proposed hybrid composite is shown in Fig. 3. The base composite is a symmetric angle-ply laminated of fiber glass/epoxy resin (3M-SP250 S29A). The elastic properties of the unidirectional layer are shown in Tab. 1. The sequence of lamination is $[45 /-45]_{15}$. The elastic modulus $\left(\mathrm{E}_{11}=\mathrm{E}_{22}\right)$ of the laminated fiber glass/epoxy resin with this sequence of lamination is $17 \mathrm{GPa}$. The loss factor, obtained by performing DMA tests (Q800 DMA, TA Instruments) on a 35x11.36x1.29 $\mathrm{mm}^{3}$ sample with a lamination sequence of [45/-45] 3 at room temperature (indicatively $20^{\circ} \mathrm{C}$ ), is $0.8 \%$ and, in the range $(1-70 \mathrm{~Hz}$ ) results not dependent on the frequency value. Two SMA sheets are embedded below the upper and the lower surface of the layered GFRP. Moreover, patterning of the SMA sheets is introduced to improve adhesion between the SMA sheets and GFRP layers, to avoid the delamination of the composite and to maximize the mechanical energy transmission to the SMA element. The geometry of the patterning is optimized with respect to the improvement in terms of the composite damping and the adhesion at SMA/glass fiber interface [15].

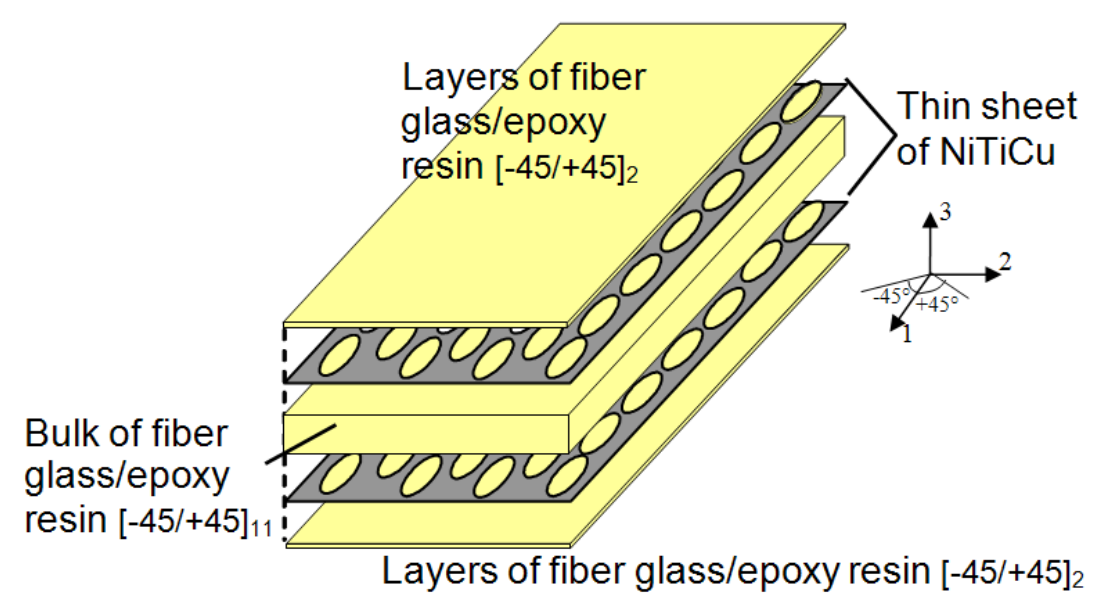

Figure 3: Architecture of the new proposed hybrid composite. 


\begin{tabular}{cccccc}
\hline \multicolumn{2}{c}{ Traction } & \multicolumn{4}{c}{ Compression } \\
$\mathrm{E}_{\mathrm{xx}}[\mathrm{GPa}]$ & $\mathrm{E}_{\mathrm{yy}}[\mathrm{GPa}]$ & $\mathrm{E}_{\mathrm{xx}}[\mathrm{GPa}]$ & $\mathrm{E}_{\mathrm{yy}}[\mathrm{GPa}]$ & $\mathrm{G}_{\mathrm{xy}}[\mathrm{GPa}]$ & $\mathrm{n}_{\mathrm{xy}}$ \\
45.7 & 13.5 & 47.8 & 12.8 & 5.4 & 0.27 \\
\hline
\end{tabular}

Table 1: Elastic properties of the fiber glass/epoxy resin 3M-SP250 S29A.

\section{SMA MATERIALS}

A $\mathrm{NiTiCu}$ and $\mathrm{CuZnAl}$ alloys are proposed for the reinfocement. $\mathrm{NiTiCu}$ is a well-known system, obtained by partial substitution of $\mathrm{Ni}$ with copper, whose damping capacity is high and stable versus the vibration time and aging effect of martensite. CuZnAl alloy has the highest damping capacity of all high damping metals [3] as well as a relatively high and appropriate modulus of elasticity. The $\mathrm{NiTiCu}$ and $\mathrm{CuZnAl}$ alloys were prepared by means of a vacuum induction melting system. The nominal atomic composition of the SMAs produced are $\mathrm{Ni}_{40} \mathrm{Ti}_{50} \mathrm{Cu}_{10}$ and $\mathrm{Cu}_{66} \mathrm{Zn}_{24} \mathrm{Al}_{10}$. The ingots were hot forged and hot and cold rolled to achieve sheets boasting a thickness of $0.3 \mathrm{~mm}(30$ $\mathrm{mm}$ in width and $400-\mathrm{mm}$ in length). The final heat treatments were $450^{\circ} \mathrm{C}$ for $1 \mathrm{~h}$, followed by a water quench and 750 ${ }^{\circ} \mathrm{C}$ for $30 \mathrm{~min}$ followed by a water quench, respectively.

Small samples, weighing about $15 \mathrm{mg}$, were subjected to Differential Scanning Calorimetry (DSC), with a heating and cooling rate of $10{ }^{\circ} \mathrm{C} / \mathrm{min}$ in the range $10-110{ }^{\circ} \mathrm{C}$ (Q100 DSC, TA Instruments). The thermographs shown in Fig. 4, outline the characteristic transformation temperatures: $\mathrm{M}_{\mathrm{f}}=32{ }^{\circ} \mathrm{C} ; \mathrm{M}_{\mathrm{s}}=49{ }^{\circ} \mathrm{C} ; \mathrm{A}_{\mathrm{s}}=52{ }^{\circ} \mathrm{C}$ and, $\mathrm{A}_{\mathrm{f}}=61{ }^{\circ} \mathrm{C}$ for the $\mathrm{Ni}_{40} \mathrm{Ti}_{50} \mathrm{Cu}_{10}$ and $\mathrm{M}_{\mathrm{f}}=50{ }^{\circ} \mathrm{C} ; \mathrm{M}_{\mathrm{s}}=63{ }^{\circ} \mathrm{C} ; \mathrm{A}_{\mathrm{s}}=60{ }^{\circ} \mathrm{C}$ and, $\mathrm{A}_{\mathrm{f}}=68{ }^{\circ} \mathrm{C}$ for the $\mathrm{Cu}_{66} \mathrm{Zn}_{24} \mathrm{Al}_{10}$. The DSC scan confirms, for both materials, the martensitic structure at room temperature.

The damping properties of the alloy were evaluated by means of dynamic mechanical analyses (Q800 DMA, TA Instruments) carried out on thin sheet $\left(12 \times 1 \times 0.15 \mathrm{~mm}^{3}\right)$ of examined materials. Different values of the frequency and strain amplitude were analysed. The specimen was subjected to a sinusoidal strain $(\varepsilon)$ with amplitude of $0.01 \%, 0.05 \%$, and $0.1 \%$ and to a oscillation frequency $(\mathrm{f})$ of $2,10,20$, and $35 \mathrm{~Hz}$. The phase lag $(\delta)$ between the applied stress and the resultant strain were measured in the temperature range $\left[-20^{\circ} \mathrm{C} \div 120^{\circ} \mathrm{C}\right]$ with a cooling/heating rate of $1{ }^{\circ} \mathrm{C} / \mathrm{min}$. As a result, the intrinsic damping $(\tan \delta)$ of the SMA was obtained as a function of the temperature.

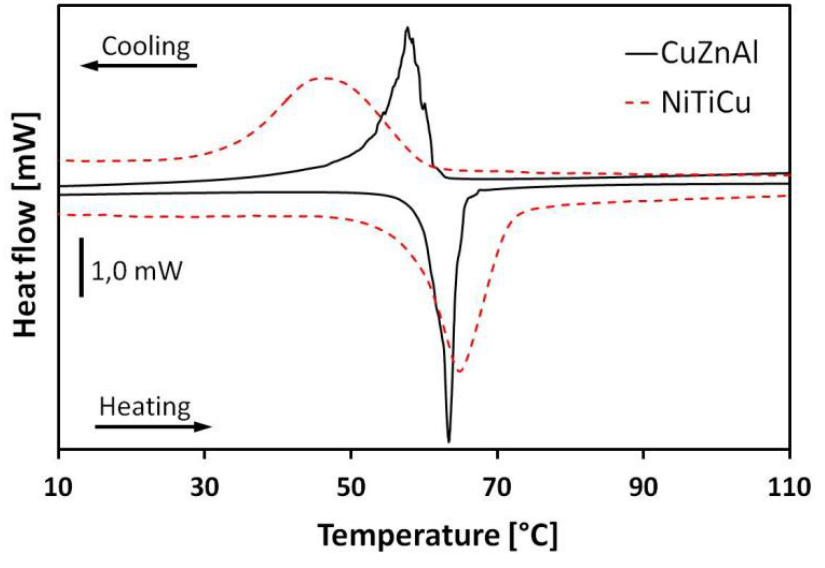

Figure 4: DSC scan of the investigated materials, heating/cooling rate: $10^{\circ} \mathrm{C} / \mathrm{min}$.

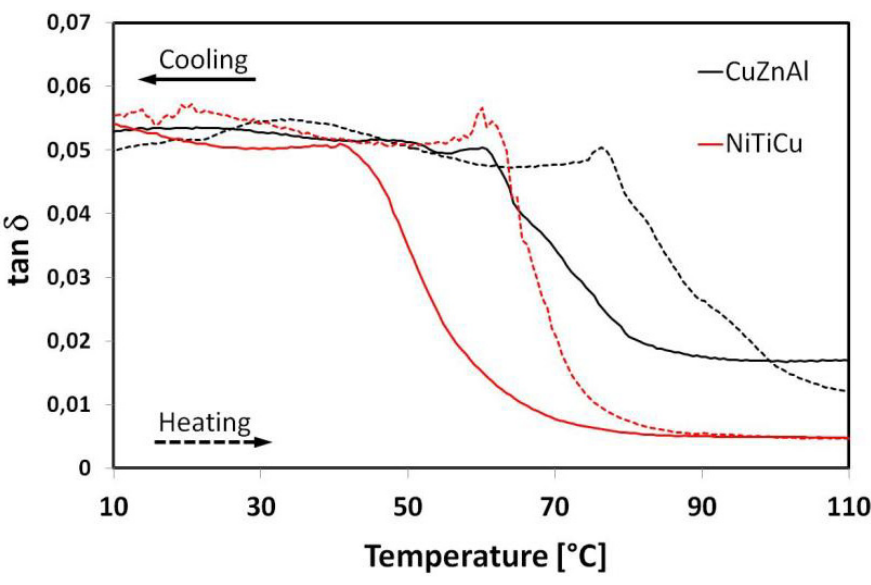

Figure 5: $\tan \delta$ vs. temperature. DMA analysis: heating rate $1{ }^{\circ} \mathrm{C} / \mathrm{min}$, frequency $10 \mathrm{~Hz}$, strain amplitude $0.05 \%$.

Fig. 5 shows the intrinsic damping tan $\delta$ as a function of temperature for an $0.05 \%$ strain amplitude, at a $10 \mathrm{~Hz}$ frequency. The high damping capacity of the martensite phase can be observed at temperatures of below the $A_{s}$ temperature, while, at higher temperatures, the parent phase (austenite phase) exhibits low tan $\delta$ values. No significant influence of frequency was observed in the range $(2 \div 35 \mathrm{~Hz})$ tested.

Owing to the fact that only a few grains were present in the cross section of the DMA specimens, results were validated through cyclic stress strain tests on larger samples. 
A MTS quasi-static testing machine with a load cell of $10 \mathrm{kN}$ is used for cyclic tension tests, at room temperature, on specimens measuring $200 \times 20 \mathrm{~mm}^{2}$. The cycle frequency is fixed as equal to $0.05 \mathrm{~Hz}$, based on the assumption that the SMA damping properties do not vary significantly at low frequencies.

A series of 16 tests was performed by controlling the cyclic elongation using a $50 \mathrm{~mm}$ gage length extensometer. The deformation amplitude ranges between $210^{4}$ and $110^{3}$, while the minimum value is about $310^{4}$. In each test, 10 cycles were run at the specified deformation amplitude.

Fig. 6 reports a comparison of the stress-strain hysteresis loop at $0.075 \%$ strain amplitude for the $\mathrm{Ni}_{40} \mathrm{Ti}_{50} \mathrm{Cu}_{10}$ and $\mathrm{Cu}_{66} \mathrm{Zn}_{24} \mathrm{Al}_{10}$ alloys. The highest damping capacity of the $\mathrm{Cu}_{66} \mathrm{Zn}_{24} \mathrm{Al}_{10}$ are clearly shown.

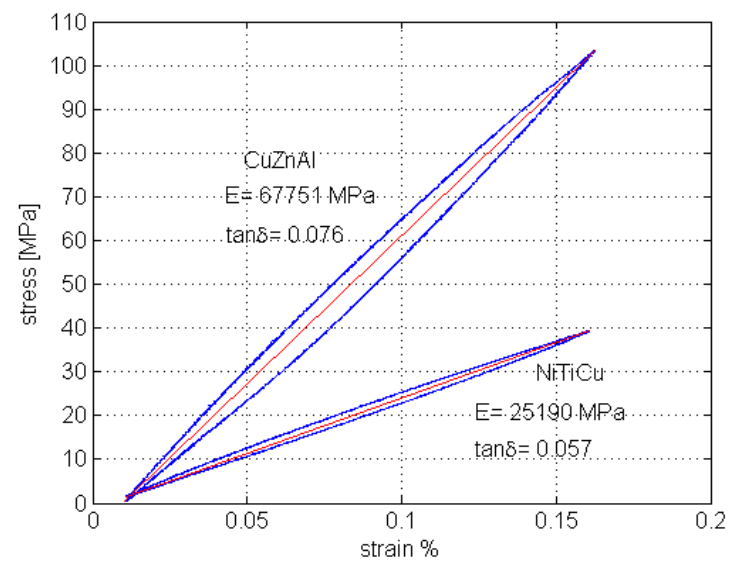

Figure 7: Stress-strain hysteresis loop for CuZnAl and NiTiCu during MTS tensile test at $0.075 \%$ strain amplitude.

The following parameters have been calculated at each strain amplitudes:

1) $\tan \delta_{i}$ value, obtained from the single cycle as:

$$
\tan \delta_{i}=\frac{\Delta W_{i}}{2 \pi W_{i}}
$$

where $\Delta \mathrm{W}_{\mathrm{i}}$ is the energy dissipated in the $i^{\text {th }}$ cycle of oscillation for unit volume, representing the area enclosed within the stress-strain hysteresis loop, and $\mathrm{W}_{\mathrm{i}}$ is the maximum stored energy in the same cycle of oscillation per unit volume;

2) storage modulus $E_{i}$, evaluated as $\Delta \sigma / \Delta \varepsilon$ from the $i^{\text {th }}$ hysteresis loop;

3) SMA specific damping capacity $\tan \delta$ and SMA storage modulus, obtained as the average values over the ten stressstrain loops performed.

The results are shown in Figs. 7 and 8 both for $\mathrm{Ni}_{40} \mathrm{Ti}_{50} \mathrm{Cu}_{10}$ and $\mathrm{Cu}_{66} \mathrm{Zn}_{24} \mathrm{Al}_{10}$. The loss factor shows an almost linear increase of the damping as a function of the strain amplitude. For $\mathrm{Cu}_{66} \mathrm{Zn}_{24} \mathrm{Al}_{10}$ a nonlinear increase at about $0.06 \%$ of strain was observed. The tan d discontinuity at $0.05 \%$ strain amplitude was also observed during DMA tests. This confirms that this particular trend of $\tan \delta$ is associated with a certain behaviour of the Cu based SMA. In order to understand this phenomenon better, accurate experiments will be performed in future developments.

By comparison of results of Fig. 7 with DMA results of Fig. 5 at a frequency of $10 \mathrm{~Hz}$, a good agreement can be observed. As shown by the results of Fig. 8, the storage modulus decreases as the strain amplitude increases.

\section{NUMERICAL ANALYSES}

$\mathrm{F}$ inite Element Analysis was used in conjunction with a Modal Strain Energy approach to study the change in the natural frequencies and the loss factor of a beam or shell, made from angle-ply laminated fiber glass/epoxy resin ([45/-45]15), when two thin sheets of the examined SMA alloy are embedded in the hybrid composite based on the architecture of Fig. 3. The hybrid composite is orthotropic with 1,2,3 as axes of orthotropy.

The Finite Element Model of the hybrid composite is a solid, beam-shaped model. The fiber glass/epoxy resin base composite $\left(200 \times 20 \times 4.6 \mathrm{~mm}^{3}\right)$ is modelled using 20 - node brick elements with reduced integration; the thin SMA sheets are modelled with eight node shell elements. The constraint between the upper and lower surface of the GFRP laminated composite and the thin SMA sheet is a tie constraint. The beam is clamped at one end (see Fig. 9). 

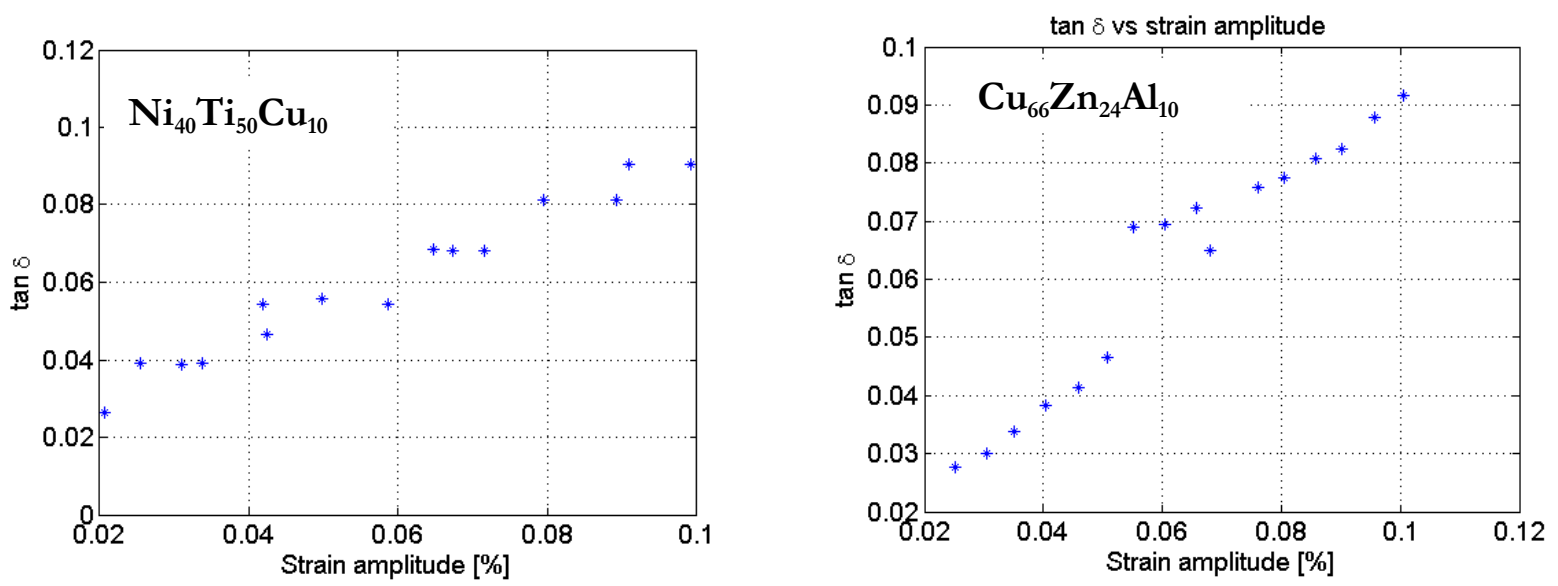

Figure 7: $\tan \delta$ vs. strain amplitude. Tensile test: $\mathrm{f}=10 \mathrm{~Hz}$, room temperature.
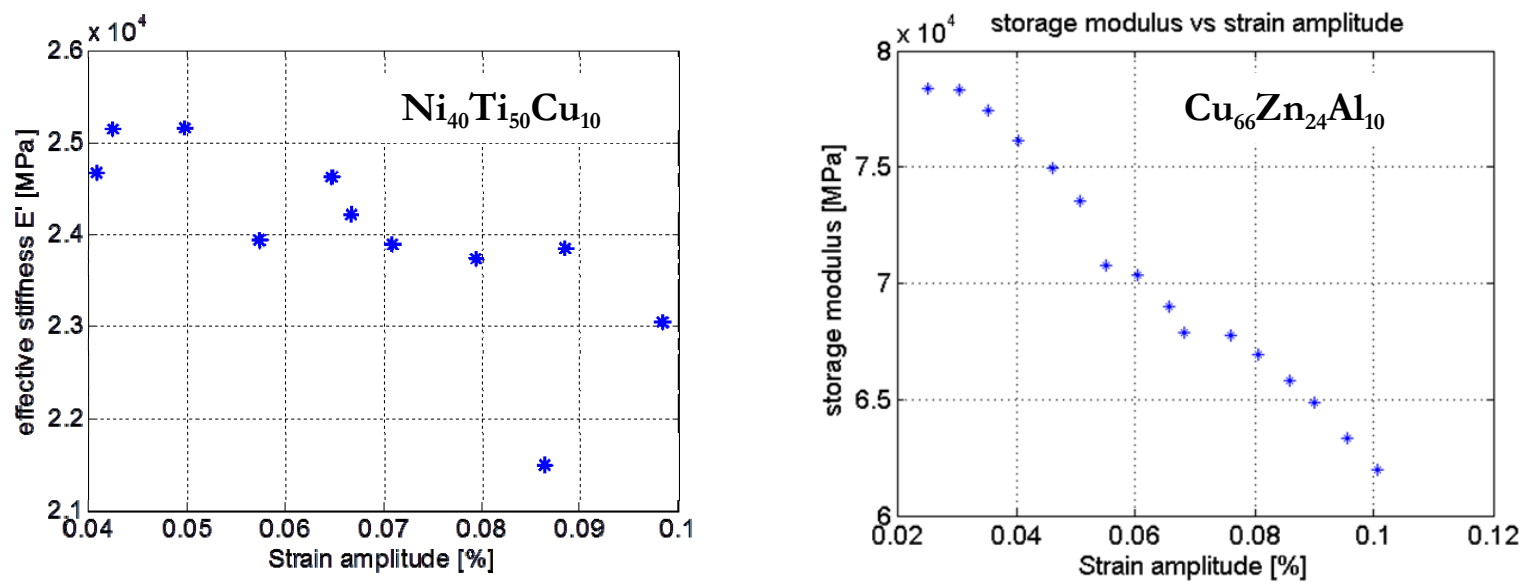

Figure 8: Storage modulus vs. strain amplitude. Tensile test: $\mathrm{f}=10 \mathrm{~Hz}$, room temperature.

A linear elastic, undamped, modal finite element analysis was performed using the Abaqus 6.7 code to extract the first natural frequency of the beam. The fiber glass/epoxy resin laminated composite has been assumed as an homogenous material having an appropriate density value and a linear elastic behaviour with an elastic modulus equal to the elastic modulus $\mathrm{E}=\mathrm{E}_{11}$ of the GFRP base composite, and a Poisson coefficient equal to $v=v_{12}$, of the angle-ply laminated fiber glass/epoxy resin (see Tab. 2). The behaviour of the SMA material has also been assumed as being linear elastic with the properties shown in Tab. 2.

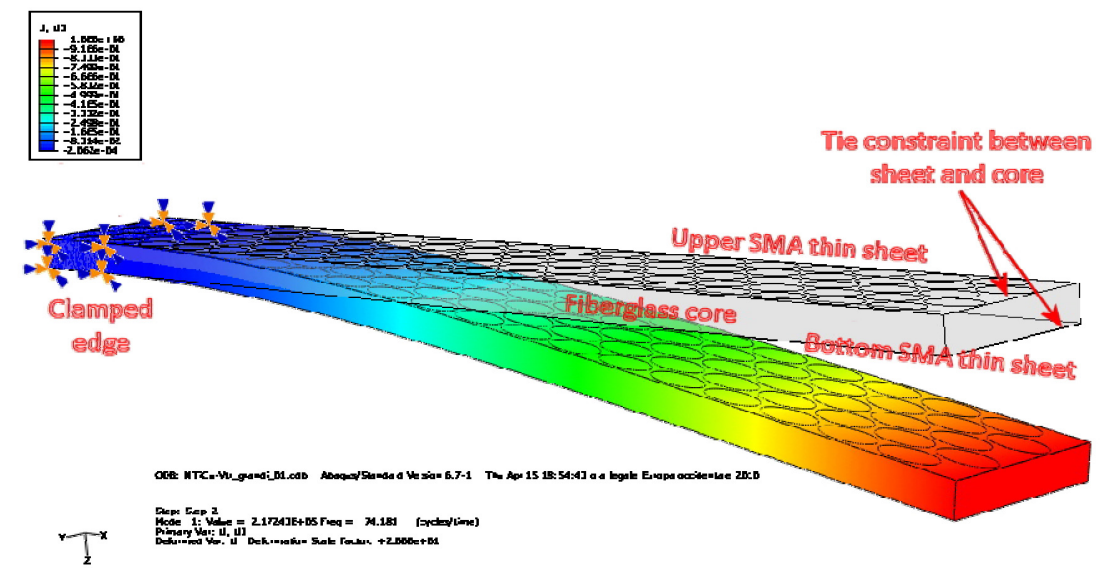

Figure 9: FEM model of the hybrid composite and first flexural deformed shape with superimpose the vertical displacement when the displacement of the free end is $1 \mathrm{~mm}$. 


\begin{tabular}{cccc}
\hline Input data & NiTiCu & CuZnAl & Glass fiber \\
Young Modulus E [MPa] & 23000 & 78000 & 17000 \\
Poisson Coefficient [-] & 0.30 & 0.20 & 0.35 \\
Density $\left[\mathrm{kg} / \mathrm{mm}^{3}\right]$ & $6.5010^{-6}$ & $7.4010^{-6}$ & $1.8610^{-6}$ \\
\hline
\end{tabular}

Table 2: Input data for the FEM analyses.
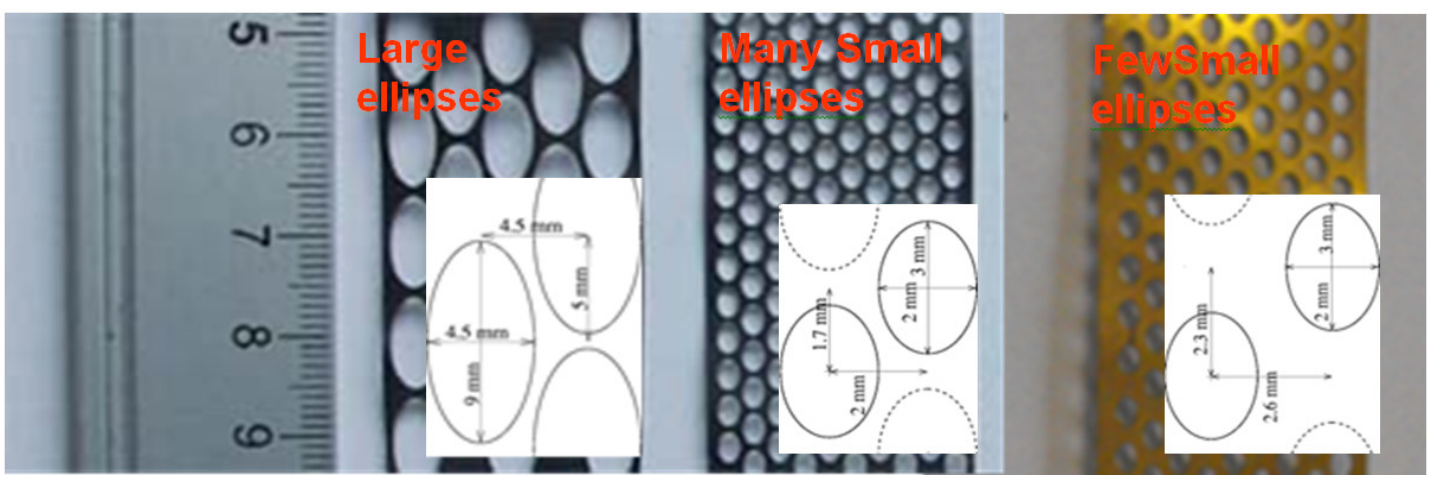

Figure 10: Thin sheets following laser micro-cutting with three different patterns, having a different SMA surface/total surface ratio.

Three different patterns of thin SMA sheets, characterized by the same elliptical shape, but having a different hole surface/SMA surface ratio are proposed (Fig. 10).

The hole surface/SMA surface ratio is equal to 2.4, 2.25 and 0.65 for the pattern named Large ellipses, Few Small Ellipses and Many Small Ellipses respectively. Likewise, for comparison, the case of thin, un-patterned SMA sheets were also considered. Given the two selected material of Tab. 2 and the geometries of the patterns shown in Figura 10, the effect of the thin sheet thickness on the first natural frequency of the beam and on the splitting of the modal strain energy between GFRP laminated composite and reinforcement was numerically investigated.

The preliminar result of the numerical analyses is about the first natural frequency. As the thickness of the fiber glass/epoxy resin base composite is kept constant $(4.6 \mathrm{~mm})$, if the thicknesses $(\mathrm{t})$ of the SMA equal to $0.1,0.2$ and 0.3 $\mathrm{mm}$, the specific weight $(\delta)$ of the hybrid composite is slightly affected by the presence of the SMA insert, and the increase of the first natural frequency with thin, patterned SMA-Large ellipse, SMA-Many Small ellipse, and SMA-Few Small ellipse, sheets is limited and almost independent on the thickness. Only for the unpatterned SMA the first natural frequency is thickness dependent and the maximum variation is about $5 \%$ when the thickness is $0.3 \mathrm{~mm}$. Results are reported in Tab. 3 for the first vibrational mode of the hybrid composite with, SMA-Large ellipses, SMA- Many Small ellipses and SMA-not patterned, $\mathrm{Ni}_{40} \mathrm{Ti}_{50} \mathrm{Cu}_{10}$ thin sheets embedded.

\begin{tabular}{lccccc}
\hline & $\begin{array}{c}\mathrm{t} \\
{[\mathrm{mm}]}\end{array}$ & $\begin{array}{c}\mathrm{f} \\
{[\mathrm{Hz}]}\end{array}$ & $\begin{array}{c}\text { atbin sheets } \\
{[\%]}\end{array}$ & $\begin{array}{c}\text { aGFRP laminated composite } \\
{[\%]}\end{array}$ & $\begin{array}{c}\tan \delta \\
{[\%]}\end{array}$ \\
$\begin{array}{l}\text { Fiberglass/ } \\
\text { epoxy resin }\end{array}$ & -- & 71.1 & -- & 100 & 0.84 \\
SMA -Large & 0.1 & 73.9 & 4.9 & 95.1 & 0.92 \\
ellipse & 0.2 & 74.1 & 8.5 & 91.5 & 1.10 \\
& 0.3 & 74.2 & 11.6 & 88.4 & 1.30 \\
SMA- Small & 0.1 & 74.1 & 6.2 & 93.7 & 1.04 \\
ellipse & 0.2 & 74.3 & 10.7 & 89.3 & 1.18 \\
& 0.3 & 74.3 & 14.4 & 85.6 & 1.30 \\
SMA-not & 0.1 & 75.5 & 15.5 & 84.5 & 1.76 \\
patterned & 0.2 & 76.6 & 26.7 & 73.2 & 1.68 \\
& 0.3 & 77.5 & 35.3 & 64.6 & 1.94 \\
\hline
\end{tabular}

Table 3: FEM analysis estimated loss factor of the hybrid composite with $\mathrm{Ni}_{40} \mathrm{Ti}_{50} \mathrm{Cu}_{10}$ thin sheets embedded. 
The second aspect investigated by numerical analyses is the percentage of modal strain energy stored in the thin SMA sheets $\left(\alpha_{\text {thin sheet }}\right)$ and in the GFRP laminated composite $\left(\alpha_{\text {GFRP laminated }}\right)$, for the first flexural mode, that is directly associated to the calculation of the loss factor of the hybrid composite $(\tan \delta)$. The Modal Strain Energy approach gives us [23]:

$$
\tan \delta=\alpha_{\text {thinsheets }} \tan \delta_{\text {thinsheets }}+\alpha_{\text {GFRPlaminatedcomposite }} \tan \delta_{\text {GFRPlaminatedcomposite }}
$$

where

- $\quad \alpha_{\text {thin sheet }}$ and $\alpha_{\text {GFRP laminated }}$ are respectively the percentage of the modal strain energy stored in the thin sheets and in the GFRP laminated composite;

- $\tan \delta_{\text {tbin sheet }}$ and $\tan \delta_{\text {GFRP laminated }}$ are the loss factors of the corresponding materials.

The loss factor of the hybrid composite was calculated according to Eq. (1) are also reported in Tab. 3.

As can be observed in the sixth column of Tab. 3, when the $\mathrm{Ni}_{40} \mathrm{Ti}_{50} \mathrm{Cu}_{10}$ patterned sheets are embedded in the composite, the loss factor is significantly enhanced. The composites with unpatterned inserts perform very well in terms of damping, but are likely to delaminate during service life [24]. As opposed to the fiber glass/epoxy resin beam, the composites with thin, inserted patterned sheets show a significant improvement in terms of damping capacity, provided that the thickness of the SMA layer is greater than $0.2 \mathrm{~mm}$. Thanks to the presence of hollow ellipses, a significant improvement in the insert/GFRP adhesion is also expected. The beam having Many Small ellipses, patterned SMA sheets gives a better performance in terms of damping.

As regards the thickness effect, it is necessary to point out that the composite loss factor increases with the thickness of the thin SMA sheets. On the other hand, technological aspects related to the laser micro-cutting process have to be considered when the sheet thickness used in the layered composite is increased. Laser cutting becomes more difficult when the thickness is considerably increased owing to the fact that the process speed has to be reduced and a multi pass strategy adopted. Both actions decrease cutting edge quality in terms of dross, roughness and thermal damage. Since finishing operations, targeted at removing the layer affected by the laser beam are intentionally disregarded because they increase process costs and time, a thickness of $0.2 \mathrm{~mm}$ seems to be a good compromise between damping and workability. A comparison between the damping performance of the hybrid composite with $\mathrm{Ni}_{40} \mathrm{Ti}_{50} \mathrm{Cu}_{10}$ and $\mathrm{Cu}_{66} \mathrm{Zn}_{24} \mathrm{Al}_{10}$ thin sheets, is reported in Tab. 4.

$\mathrm{Cu}_{66} \mathrm{Zn}_{24} \mathrm{Al}_{10}$ thanks to its higher storage modulus stores up to $25 \%$ of the elastic energy of the deformed beam with respect to the $10 \%$ of the modal strain energy stored by the $\mathrm{Ni}_{40} \mathrm{Ti}_{50} \mathrm{Cu}_{10}$ reinforcement with the same Many Small Ellipses patterns. As consequence the higher specific damping of the $\mathrm{Cu}_{66} \mathrm{Zn}_{24} \mathrm{Al}_{10}$ alloy participate with a greater contribution to the enhancement of the structural damping of the hybrid composite

Moreover a modification of the pattern, from the SMA_Many Small Ellipses to the SMA_Few Small Ellipses, with a hole surface/SMA surface ratio is equal to 0.65 (see Fig. 11), allows a further significant increase of the modal strain energy stored in the SMA thin sheets and of the final structural damping of the composite.

\begin{tabular}{|c|c|c|c|c|c|}
\hline & $\begin{array}{c}\mathrm{t} \\
{[\mathrm{mm}]}\end{array}$ & $\begin{array}{c}\mathrm{f} \\
{[\mathrm{Hz}]}\end{array}$ & $\begin{array}{c}\alpha_{\text {tbin sheets }} \\
{[\%]}\end{array}$ & 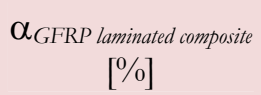 & $\begin{array}{c}\tan \delta \\
{[\%]}\end{array}$ \\
\hline $\begin{array}{l}\mathrm{Ni}_{40} \mathrm{Ti}_{50} \mathrm{Cu}_{10}- \\
\text { Many Small ellipse }\end{array}$ & 0.2 & 74.3 & 10.7 & 89.3 & 1.18 \\
\hline $\begin{array}{l}\mathrm{Cu}_{66} \mathrm{Zn}_{24} \mathrm{Al}_{10}- \\
\text { Many Small ellipse }\end{array}$ & 0.2 & 66.1 & 25 & 75 & 1.60 \\
\hline $\begin{array}{l}\mathrm{Cu}_{66} \mathrm{Zn}_{24} \mathrm{Al}_{10}- \\
\text { Few Small ellipse }\end{array}$ & 0.2 & 69 & 37 & 69 & 2.04 \\
\hline
\end{tabular}

Table 4: FEM analysis estimated loss factor of the hybrid composite, comparison between $\mathrm{Ni}_{40} \mathrm{Ti}_{50} \mathrm{Cu}_{10}$ and $\mathrm{Cu}_{66} \mathrm{Zn}_{24} \mathrm{Al}_{10}$ thin sheets embedded.

These numerical results have been validated by experimental decay tests performed on sample of the proposed new composite. The experimental tests are described in detail in [13, 25]. 


\section{SMA/GFRP LATERAL HORN}

he new architecture of a SMA/GFRP hybrid composite profile is proposed for the design of an SMA/GFRP lateral horn.

In this case the host composite is a symmetric angle-ply laminate of fiber glass/epoxy resin with a stacking sequence of $(45 /-45)_{n}$, where $\mathrm{n}$ varies, thus accounting for the variation in the horn thickness, ranging from 49 (thicker section) to 24 at the opposite end. On the basis of the results of the previous paragraph a $\mathrm{Cu}_{66} \mathrm{Zn}_{24} \mathrm{Al}_{10}$ material and the Few Small Ellipses pattern has been selected for this application. As regards the thickness effect, it is necessary to point out that the composite loss factor increases with the thickness of the SMA sheets. Even if laser micro-cutting becomes more difficult when the thickness increases, a thickness of $0.3 \mathrm{~mm}$ has been adopted in order to take the maximum advantage from the passive damping of the SMA reinforcements.

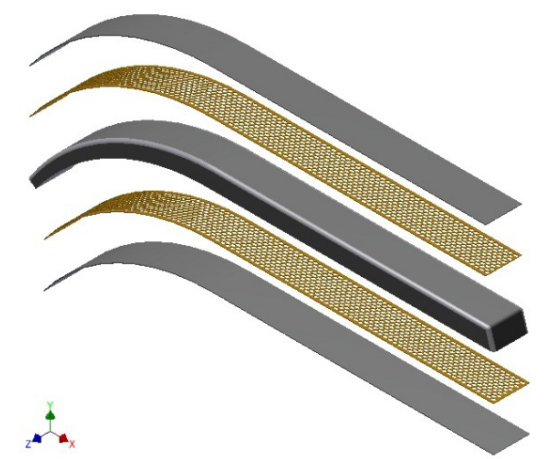

Figure 11: Architecture of the SMA//GFRP hybrid composite horn. Grey $[-45 /+45]_{\mathrm{n}}$ layered GFRP host composite. Brown: Embedded CuZnAl SMA thin patterned sheets.

A prototype of the horn has been made. Firstly, the regular pattern of elliptical holes has been produced by means of laser cutting using a pulsed nanosecond fiber laser (IPG Photonics YLP50). The process parameters used to perform the micro-cutting process of the elliptical pattern are shown in Tab. 5.

The maximum average power available, together with the highest pulse frequency and process speed were chosen to ensure through cutting and reduced thermal damage. A double laser pass strategy was required in order to guarantee stable cutting through the entire thickness of the SMA sheet [26].

\begin{tabular}{cccc}
\hline $\begin{array}{c}\text { Process speed } \\
{[\mathrm{mm} / \mathrm{s}]}\end{array}$ & $\begin{array}{c}\text { Average power } \\
{[\mathrm{W}]}\end{array}$ & $\begin{array}{c}\text { Pulse frequency } \\
{[\mathrm{kHz}]}\end{array}$ & Shielding gas \\
5 & 50 & 80 & Argon at 5 bar
\end{tabular}

Table 5: Main process parameters used in laser micro-cutting of the elliptical pattern.

In the second step, the laminated composite is assembled. The horn mould is filled first with four layers [+45/-45] of unidirectional fiber glass/epoxy resin and covered with the first patterned thin SMA sheet; the sequence of lamination $[+45 /-45]_{\mathrm{n}}$ is added and covered by the second thin SMA sheet and by an additional four layers [+45/-45] $]_{4}$ of unidirectional fiber glass/epoxy resin. As previously reported, parameter $\mathrm{n}$ is dependent on the thickness of the cross section along the axis of the horn. Any air bubbles are eliminated by means of a vacuum bag and the hybrid composite is then cured in an autoclave.

In order to study the dynamic properties of the proposed hybrid layered architecture and to evaluate the improvement of the damping capacity due to the introduction of the SMA insert, three samples of the horn were produced. The first one was manufactured as described, while the second one was produced using the same architecture as the first one. However, in this case, commercial brass sheets were used in the place of the SMA sheets. The third one was only made with GFRP. Manufacture of an extra horn with a commercial brass insert is targeted at evaluating/excluding any possible contribution of a metal sheet/host composite interface to the damping of the SMA hybrid composite horn. As shown in Fig. 12, following the cure cycle in an autoclave, the three horn samples are completed. 


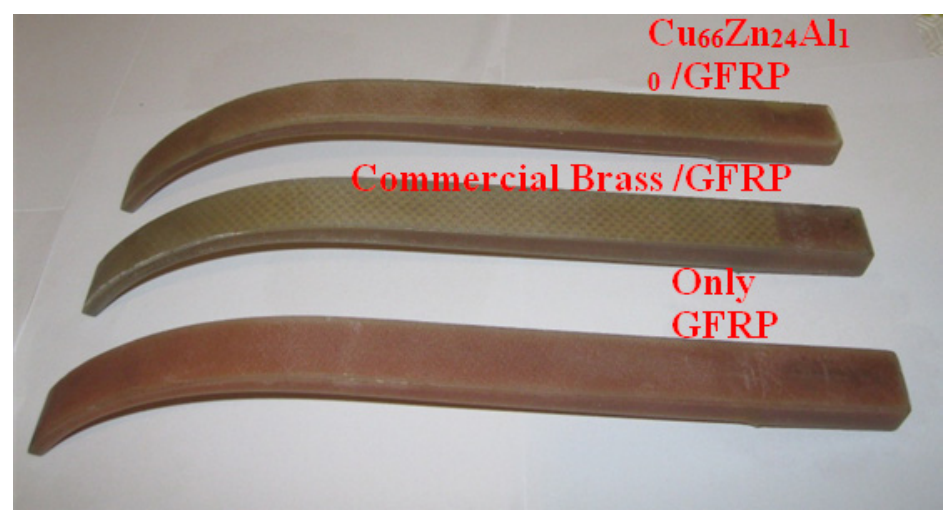

Figure 12: Final appearance of the three horn samples.

\section{EXPERIMENTAL TESTS}

$\mathrm{T}$ he non-dimensional damping, related to the first flexural mode of the three horns manufactured, was experimentally measured by performing a series of decay tests with the horn in a single cantilever configuration.

During the tests, the end of the horn, designed to be connected to the structure of the collector, was clamped on a steel fixture, while the other end was loaded with an initial vertical displacement and then released to oscillate freely [22]. The transient response was recorded in terms of the vertical displacement of the section of the horn at a distance of 150 $\mathrm{mm}$ from the clamp. The displacement was measured by means of a lase-triangulation sensor (MEL M5L/10).

The non dimensional damping was evaluated as follows:

$$
h_{n}=\frac{\delta_{n}}{2 \pi} \quad \text { where } \quad \delta_{n}=\ln \left(\frac{x_{n}}{x_{n+1}}\right)
$$

where $\delta_{\mathrm{n}}$ is the logarithmic attenuation coefficient, $x_{n}$ is the vertical displacement amplitude of the horn at $150 \mathrm{~mm}$ from the clamping at the $n^{\text {th }}$ oscillation of the transient response and $x_{n+1}$ is the same displacement amplitude at the $(n+1)^{t+h}$ oscillation. During transient decay, the amplitude of each successive oscillation decreases, meaning that Eq. (2) allows us to obtain the dependence of the non-dimensional damping from the displacement amplitude.

In order to compare the non-dimensional damping (h) with the loss factor $(\tan \delta)$, assumed as an index of the intrinsic damping in section Design considerations, the following consideration can be made.

The loss factor $(\tan \delta)$ of the oscillatory beam, considered as a single degree of freedom system, is defined as the ratio

$$
\tan \delta=\frac{E_{d}}{2 \pi U}
$$

where $E_{d}$ is the energy loss per cycle and $U$ is the strain energy.

Assuming that the motion is entirely due to the first flexural mode

$$
\begin{aligned}
& U=\frac{1}{2} k_{1} q_{1}^{2} \\
& E_{d}=\pi \cdot c_{1} \omega_{1} q_{1}^{2}
\end{aligned}
$$

where $k_{1}$ is the modal stiffness, $q_{1}$ is the modal coordinate, $c_{1}$ is the modal damping, and $\omega_{1}$ is the frequency of the first flexural mode of the beam.

On account of $k_{1}=m_{1} \omega_{1}^{2}$ where $m_{1}$ is the modal mass of the beam and, from the definition of non-dimensional damping $c_{1}=h_{1}\left(2 m_{1} \omega_{1}\right)$, Eq. (3) can be rewritten as:

$$
\tan \delta=\frac{\pi \cdot c_{1} \omega_{1} q_{1}^{2}}{2 \pi \frac{1}{2} k_{1} q_{1}^{2}}=\frac{h_{1}\left(2 m_{1} \omega_{1}\right) \omega_{1} q_{1}^{2}}{\pi m_{1} \omega_{1}^{2} q_{1}^{2}}=2 h
$$


Eq. (6) recalls that the loss factor is equal to twice the non-dimensional damping value.

The natural frequency of vibration of the first flexural mode can be identified by Fourier transform of the waveform of the transient response of the horns acquired during the decay tests reported in Fig. 13. In this figure, the transient response of the horn with a Commercial brass patterned insert is actually superimposed on the only GFRP horn and, for sake of clarity, is not reported. The first natural frequencies of the three horn samples are shown in Tab. 6 and are not affected by the integration of the SMA/Commercial brass. The total weight of the horns is also reported in the same table and is only slightly affected by the integration of the SMA/Commercial brass. As will be shown below, the reduced thickness of the SMA/Commercial brass sheets and the patterns with a ratio between the surface of the holes and the total surface of the SMA sheet, equal to 0.65 , not only allows us to maintain the structural and dynamic behaviour of the component but also to improve the damping capacity.

The beneficial effect of the integration of an SMA insert in the host GFRP horn on its damping capacity is apparent in Fig. 13.

The horn manufactured as an SMA/GFRP hybrid composite has a larger logarithm attenuation coefficient of the first flexural mode both as regards the horn made only from GFRP as well as the one manufactured as a Commercial brass/GFRP hybrid composite. As previously mentioned in Fig. 13, the transient response of the latter two is practically superimposed.

The results of experimental non-dimensional damping, associated with the first flexural mode, calculated from the logarithmic decrement of Fig. 13 when the displacement is equal to $1 \mathrm{~mm}$, are shown in Tab. 7.

The comparison between the non dimensional damping of the Only GFRP horn and the non dimensional damping of the horn with commercial Brass reinforcement allows us to exclude any significant contribution of the metal sheet/host composite interface to the damping of the SMA hybrid composite horn.

When the SMA patterned sheets is embedded in the composite, due to its high specific damping the non-dimensional damping of the horn is significantly enhanced.

\begin{tabular}{ccc}
\hline & First natural frequency & Total weight of the horn \\
& {$[\mathrm{Hz}]$} & {$[\mathrm{g}]$} \\
Only GFRP & 75.5 & 168 \\
Commercial brass/GFRP & 75.3 & 182 \\
SMA/ GFRP & 74.8 & 180 \\
\hline
\end{tabular}

Table 6: First natural frequency and total weight of the three horn samples.

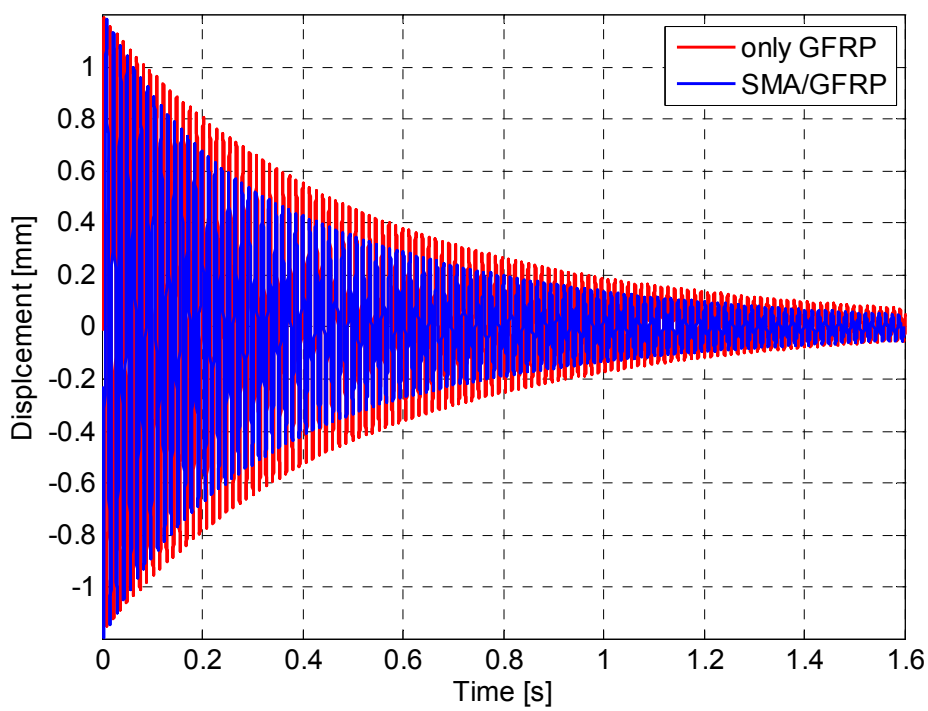

Figure 13: Transient of the displacement in the section at $150 \mathrm{~mm}$ from the clamped section, for the horn with a SMA patterned insert and for the horn made only from GFRP. 


\begin{tabular}{ccc}
\hline Horn & Tan $\delta$ & $\mathrm{h}$ \\
Only GFRP & 0.8 & 0.4 \\
Commercial Brass & 0.84 & 0.42 \\
$\mathrm{Cu}_{66} \mathrm{Zn}_{24} \mathrm{Al}_{10} /$ GFRP & 1.4 & 0.7 \\
\hline
\end{tabular}

Table 7: Tan $\delta$ e non-dimensional damping (h) for the three horns when the displacement is equal to $1 \mathrm{~mm}$.

\section{CONCLUSIONS}

o enforce the application of SMA alloys for passive damping in mechanical systems, shape memory alloy-based composites with thin, embedded, patterned SMA sheets were numerically optimized and fabricated. It has be shown that the new architecture of the hybrid composite is applicable to improve the structural damping of the host GFRP laminated, without significant changes of the specific weight and of the flexural stiffness. A salient result of this study is that the proposed hybrid composite architecture can be used for passive control of GFRP slender structure. Patches of patterned SMA thin sheets can be embedded only in the area of highest deformation of the GFRP structure according to the considered modal shape, to improve their passive damping capacity without any design modification and significant effects on the dynamic behaviour.

The pattern of the thin SMA sheets proved to be a key feature in the optimization process of the flexural stiffness, weight and damping capacity of the hybrid composite. At the same time, this feature plays a positive role in the improvement of adhesion, and in the load transfer, between the GFRP laminated composite and the SMA reinforcements.

The application of the proposed hybrid composite for a new design of a GFRP lateral horn of a railway pantograph has been proposed. A first prototype of the horn was manufactured. The salient points of the manufacturing process included the production of a CuZnAl SMA alloy having an appropriate transformation temperature; the laser microcutting of the CuZnAl SMA sheets and the fabrication of the component without any purpose-made alignment device.

\section{ACKNOWLEDGMENT}

he authors would like to thank Mako Shark S.r.l-Viale Montecuccoli 18, 23843 Dolzago (LC), Italy, for manufacture of the laminated horns.

\section{REFERENCES}

[1] K. Otsuka, C.M. Wayman, Shape Memory Materials, Cambridge University Press, Cambridge, (1998).

[2] A. Biscarini, B. Coluzzi, G. Mazzolai et al., J. Alloys Compd., 356 (2003) 669.

[3] M.O. Moroni, R. Saldivia, M. Sarrazin, A. Sepulved, Material Science and Engineering, A335 (2002) 313.

[4] Y.H. Li, S.W. Liu, H.C. Jiang, et al., Journal of Alloy and Coumponds, 430 (2007) 149.

[5] J. Van Humbeeck, J. Alloys Compd., 355 (2003) 58.

[6] J. Van Humbeek, S. Kustov, Smart Mater. Struct., 14 (2005) 171.

[7] J. Raghavan, T. Bartkiewicz, S. Boyko, M. Kupriyanov, et al., Composites: Part B, 41 (2010) 214.

[8] Ya Xu, K.Otsuka, H.Yoshida, H.Nagai, R.Oishi, H.Horikawa, T.Kishi, Intermetallics, 10 (2002) 361.

[9] R. Zhang, Q. Q. Ni, A. Masuda, T. Yamamura, M. Iwamoto, Composite Structures, 74 (2006) 389.

[10] Rogers CA, Liang C, Barker D. In: Proceedings of US Army Research Office Workshop on Smart Materials, Structures, and Mathematical Issues, Blacksburg, USA (1988) 39.

[11] M. Dolce, D. Cardone, Int. J. of Mechanical Sciences, 47 (2005) 1693.

[12] D.S. Li, X.P. Zhanga, Z.P. Xionga, Y.-W. Mai, Journal of Alloys and Compounds, 490 (2010) L15.

[13] C.A. Biffi, P. Bassani, A. Tuissi, M. Carnevale, N. Lecis, A. Lo Conte, B Previtali, Functional Materials Letters, 5(1) (2012) 1250014.

[14] G. Zhou, P. Lloyd, Composites Science and Technology, 69 (2009) 2034.

[15] Y. Matsuzaki, T. Ikeda, C Boller, Smart Mater. Struct., 14 (2005) 343 
[16] F. Taheri-Behrooz, F Taheri, R. Hosseinzadeh, Material and Design, 32 (2011) 2023.

[17] A. Collina, S. Melzi, In: AITC-AIT, Conference, Parma, Italy, (2006).

[18] A. Collina, A. Lo Conte, M. Carnevale, Proc. IMechE Part F: J. Rail and Rapid Transit, 223 (2009) 1.

[19] S.K. Wu, H.C. Lin, Journal of Alloys and Compounds, 355 (2003) 72.

[20] C. Remillat, M. R. Hassan, F. Scarpa, Transactions of the ASME, 128, (2006), 260.

[21] A. Tuissi, P. Bassani, A. Casati, M. Bocciolone A. Collina, M. Carnevale, A. Lo Conte, B. Previtali, JMEPEG, 18 (2009) 612.

[22] K.T. Lau, A. W.Chan, S. Q. Shi, L. M. Zhou, Materials and Design, 23 (2002) 265.

[23] G. Lepoittevin, G. Kress, Materials and Design, 31 (2010) 14.

[24] Q. Q. Ni, R. Zang, T. Natsuki, M. Iwamoto, Composites Structures, 2007 (79) 501.

[25] P. Bassani, C.A. Biffi, M. Carnevale, N. Lecis, B. Previtali, A. Lo Conte, Materials and Design, 45 (2013) 88.

[26] B. Previtali, S. Arnaboldi, P. Bassani, et al., In: 10 ${ }^{\text {th }}$ Biennial Conference on Engineering Systems Design and Analysis, ESDA 2010, Istanbul (2010). 